\title{
Orientação Profissional sobre a Ótica do Tempo
}

Eliane Filgueiras ${ }^{1}$

Resumo: A relação da humanidade com o tempo reflete uma constante necessidade desta de situar-se a partir da linearidade temporal. É a partir desta linearidade que o sujeito internaliza e concebe o conceito de tempo e sente que existe lógica naquilo que conhece enquanto passado, presente e futuro. $\mathrm{O}$ processo de Orientação Profissional demonstra quais as diferentes repercussões da relação que o sujeito estabelece com o seu tempo lógico no movimento de escolha profissional. O presente artigo pretende apontar algumas implicações desta inter relação entre tempo e escolha.

Palavras - chaves: Orientação profissional; temporalidade; tempo lógico; escolha;

\section{Introdução:}

É tempo de pensar qual o significado do tempo num mundo no qual o tempo além de urgir é dinheiro e faça bom ou mau tempo ninguém, mesmo ao seu tempo, tem tempo de aproveitar o tempo.

A palavra tempo em nossa língua ganha muitos significados. Michaelis traz algumas definições:

tempo :s. m. 1. Medida de duração dos seres. 2. Uma época, um lapso de tempo futuro ou passado. 3. A época atual. 4. A idade, a antiguidade, um longo lapso de anos. 5. Ocasião própria; ensejo, conjuntura, oportunidade. 6. Sazão, quadra. 7. Estado meteorológico da atmosfera; vento, ar, temperatura. 8. Gram. Flexão que indica o momento de ação dos verbos. 9. Mús. Cada uma das divisões do compasso. 10. Mús. Movimento com que se deve executar um trecho musical e que se indica por meio de determinadas expressões.

O amplo emprego da palavra tempo pode de certo modo refletir a grande preocupação da humanidade em relação ao tema.

O tempo é em si um conceito abstrato, foi criado pelo homem juntamente a uma forma de mensurá-lo.A necessidade de medir o tempo, de compreendê-lo e conseqüentemente controlá-lo reflete uma aparente inquietação da humanidade, em relação a ele.

\footnotetext{
${ }^{1}$ Psicóloga Graduada pela UFPR, com especialização em Psicanálise Clínica pela PUCPR.
} 


\section{O que poderia causar tal inquietação?}

A noção de tempo esta vinculada ao movimento. Por vezes quando não fazemos nada dizemos que o tempo não passa. De fato a marca de que o tempo, mesmo que em sua abstração, existe, é a prova de que as coisas não estão sempre no mesmo lugar, de que estão em movimento.

Talvez não seja coincidência a palavra tempo também definir alterações meteorológicas, pois estas são certamente, um indício de que a vida está em constante movimento. As sucessões de dias e noites, primaveras e invernos mostram ao homem o dinamismo do mundo.

Muitas vezes a passagem de tempo se relaciona a maturação, envelhecimento e conseqüente finitude das coisas. Ver a dinâmica da vida caminhar para o fim, pode de certo modo, ter gerado a tentativa de controlar o tempo e porque não dizer, assim também controlar a morte.

Presenciar nascimentos, crescimentos e mortes, indícios de que o tempo existe, fez com que a humanidade concluísse também que o tempo passar gera tudo isto.Se o tempo surge a partir da observação do ciclo da vida, este somente passa a ser possível devido à passagem de tempo.

Por vezes ouvimos o senso comum se referir ao tempo como um sujeito em si, uma entidade cuja qual não se deve lutar e que é implacável. O tempo tira a juventude e traz a velhice e a morte. $O$ tempo que passa jamais pode ser resgatado.Nestas frases percebe-se o reflexo de um certo temor ao tempo futuro, pois este conduz a vida por caminhos desconhecidos.

Se analogamente transpusermos a relação da humanidade com o tempo à relação do adolescente com o tempo veremos algumas semelhanças.

A adolescência é por definição uma fase da vida cujas alterações físicas e emocionais permitem chamá-la de fase de transição da vida infantil para a vida adulta.

"nesta epoca em que o adolescente busca reconstruir-se como sujeito de sua vida, ele precusa também escolher uma profissão e submeter-se a uma vestibular, que talvez hoje, possamos considerar como um rito de passagem à vida adulta.Estas situações,que se acumulam, caracterizam este momento como estressante."Lassance, 1999,p.88.

Como o adolescente trabalha com a questão do tempo?

Perceber as mudanças que ocorrem em seu próprio corpo, obriga os adolescentes a constatarem que o tempo está passando e que aos poucos, a criança desaparecerá e o adulto surgirá. Neste momento para o adolescente é como se tudo aquilo que ele considera certo precisasse ser repensado. Todas as certezas 
infantis, e toda a sensação de segurança que geralmente acompanham as certezas, começam a ser questionadas.

A sensação de ansiedade frente esta ruptura com o universo infantil associada à ansiedade frente às incertezas do universo adulto podem gerar no adolescente uma sensação de desnorteamento e confusão que irá interferir diretamente nas escolhas realizadas.

Ao inicio de um atendimento em Orientação Profissional, muitos são os relatos que trazem sentimentos como incertezas e insegurança.Palavras como desnorteado, confuso, indeciso, perdido permeiam o discurso destes adolescentes.

As decisões pertinentes a esta nova fase de transição da vida infantil para a vida adulta, são tomadas não apenas com base no que o adolescente quer mas também com base em quem o adolescente quer ser.

Constantemente ao longo do trabalho vemos os adolescentes relacionarem a questão da escolha profissional à escolha de um futuro.

O tempo associa-se a passado, presente e futuro. A relação que o adolescente estabelece com estes tempos vai de certo modo indicar a relação que este terá com a sua escolha profissional.

Ao falar do passado, os adolescentes relatam não apenas fatos, mas principalmente a forma como estes fatos marcaram a sua vida e qual a significação e valor que estes fatos adquiriram.Será com base na relação estabelecida com o meio, que o sujeito construirá o seu universo conceitual e a partir daí significara e contextualizará suas novas experiências de vida.

Uma orientanda em trabalho de OP que será denominada D trouxe por inúmeras vezes o quanto acreditava que na vida as pessoas não deveriam se preocupar com coisas que nomeara de fúteis. Entre estas coisas estavam conceitos como realização pessoal, felicidade no trabalho, fazer o que gosta.

Para a orientanda a vida adulta implicava em se preocupar com as coisas práticas, como pagar contas e assim ter um certo grau de conforto e segurança.

Ao longo das sessões. D traz uma infância cercada de dificuldades financeiras e a imagem de um pai sempre sonhador e incapaz de arcar com as obrigações da casa e uma mãe sempre trabalhadora que faz o que não gosta em sua profissão, mas que abdicou de realizar-se para sustentar a casa.

A escolha de D em relação à sua profissão, perspassava as seguintes possibilidades; fazer Psicologia que segundo ela define-se de modo pouco prático devido ao caráter existencial da profissão, e fazer Pedagogia que implica em formar-se e ter emprego garantido.

D afirma querer Psicologia, mas afirma que não tem coragem para tentar pois é muito concorrido e acha que acabara fazendo Pedagogia, pois a concorrência é menor e lhe dá mais garantias de passar no vestibular. 
Neste exemplo, a representação simbólica de D de "pai fútil , mãe útil", atrelada a uma história de vida na qual o pai não sustenta a família e abandona a casa delegando à mãe a função de dar estabilidade ao lar, nada mais natural que $\mathrm{D}$ sinta-se impelida a acreditar que coisas fúteis não garantam futuro.Sendo assim opta por uma profissão que lhe garanta estabilidade.

Logo, a interferência direta da relação do sujeito com o seu passado e do referencial simbólico que este passado representa na escolha da profissão, indica um ponto a ser trabalhado ao longo do processo de OP.

Por muitas vezes no trabalho com adolescentes, presenciamos dificuldades no processo de escolha geradas a partir da relação do sujeito com o tempo passado.

De um modo geral o apego inadequado ao tempo passado, reflete-se em uma conduta imatura. $\mathrm{O}$ adolescente que vê nos mecanismos infantis a única forma de se relacionar com o mundo acaba por não encarar a realidade de que esta crescendo e que terá que estabelecer novas formas de se relacionar com o meio.

Postergar a escolha, ou simplesmente não se dar conta de que será preciso escolher, o que Bohoslavisky denominou como fase pré dilemática, pode ser reflexo de um apego inadequado ao tempo passado.Segundo Bohoslavisky:

“A situação pré dilemática é aquela por que passa o adolescente que não se dá conta de que deve escolher.Estes são os casos em que o adolescente é trazido à entrevista e, uma vez nela, não consegue imaginar qual a dificuldade que os outros supões que ele tem.Trata-se de uma imaturidade tal que o caso terá que ser encaminhado a uma psicoterapia..." (p.84)

Resgatando o exemplo de $\mathrm{D}$, verifica-se um apego à forma de pensamento infantil que por muitas vezes deve ter tornado possível a ela compreender da maneira menos ansiogenica possível os fatos que marcaram sua infância.

Já na adolescência, D deveria ser capaz de substituir esta forma de pensamento primário, por outras mais elaboradas, que utilizassem como recursos fatos da realidade apreendidos ao longo do seu desenvolvimento.Não foi isto o observado. $\mathrm{D}$ ao longo do processo mostrou-se alheia a informações quanto ao caráter "fútil" da Psicologia ou "útil" da Pedagogia, ou seja, as informações em relação aos cursos e profissões foram ignoradas na sua lógica peculiar infantil.

Verifica-se neste caso uma relação direta da relação do sujeito com o passado e o processo de escolha profissional a ser proposto no momento presente.No caso $\mathrm{D}$, sessões com caráter meramente informativo não teria grande 
valia, pois a possibilidade de confrontação com dados da realidade está neste caso diretamente vinculada a sua estruturação infantil.

Repensar esta condição possibilita nortear inclusive as técnicas utilizadas no trabalho para que estas técnicas alcancem seus objetivos de modo mais eficaz.

Em alguns discursos, verifica-se um resgate recorrente a episódios do passado nos quais os adolescentes investem toda a sua energia e deixam, portanto de se colocarem questões recentes pertinentes à sua fase atual. Este mecanismo pode ser considerado tipicamente de defesa, pois visa não confrontar o EGO com situações geradoras de desequilíbrio.

Por outro lado o movimento constante de recordar o passado pode ser uma forma de se preparar para o futuro.

A capacidade de armazenar informações, o que vamos definir como memória, dá ao sujeito a noção de tempo.

Além do dinamismo necessário para a percepção de que o tempo, mesmo em sua abstração, existe é necessário à capacidade de reter as diferentes informações.

A capacidade de reter infamações possibilita uma posterior confrontação do material armazenado com o material ofertado pela realidade presente.Este movimento possibilita ao sujeito internalizar a sensação de tempo passado presente e assim conceber a possibilidade de futuro e até mesmo criar expectativas quanto a ele.

Esta relação de memória e tempo pode ser mais bem observada nos casos de patologia. O filme Amnésia, memento-2001-de Christophaer Nolan, baseado na história de Jonathan Nolan, conta a história de um homem com um distúrbio que acarretava em perda de memória recente. Ele era capaz de se lembrar de fatos de seu passado, até o momento em que sofrera um acidente, era, portanto capaz de saber quem era, porém após o acidente deixou de ser capaz de reter informações recentes.

No filme uma cena relata de modo claro esta relação entre memória e tempo. Nesta cena uma mulher insulta o sujeito a ponto de fazer com que ele a agrida fisicamente. Ela sai da sala e retorna instantes depois dizendo que outra pessoa havia feito aquilo e que ele estará esperando por ela até então.Ele acreditou.

A impossibilidade de reter as experiências mantidas com o meio impossibilita também constituir a sensação de linearidade dos fatos que norteia a concepção de tempo.

Talvez por isto Nolan, tenha editado o filme de modo atemporal, com cenas do final intercalando cenas do inicio. A intenção talvez tenha sido causar 
naquele que assiste a mesma sensação de inexistência de tempo, e conseqüente inexistência de lógica na vida daqueles que não tem memória.

$\mathrm{O}$ resgate constante a memórias infantis, pode ser uma forma de o adolescente organizar os fatos de sua memória, e a partir daí empiricamente, compreender os acontecimentos do presente e arriscar-se a idealizar um futuro.

Mais do que o conceito freudiano, da necessidade de recordar repetir para reelaborar, recorrer à memória quando se depara com uma nova situação, torna possível ao adolescente internalizar a noção de tempo e suas variações, ou seja, passado, presente e futuro.

Uma nova alusão ao caso $\mathrm{D}$ pode exemplificar melhor esta idéia. D conta o quanto se sentiu perdida e amedrontada no seu primeiro dia de aula em uma escola publica. Conta que depois chorou quando teve que se mudar para outra escola. $\mathrm{Na}$ seqüência $\mathrm{D}$ relaciona aquele medo frente a algo que não conhecia ao medo que sente agora em relação à universidade.O alinhamento de fatos inseridos em um contexto temporal propiciou não apenas uma nova percepção dos sentimentos do presente, mas principalmente, possibilitou a D inferir acerca de seu futuro.

A relação do adolescente que se apresenta à Orientação Profissional é geralmente de descontentamento com seu estado atual.

Os adolescentes relatam sentimentos de desorientação, e talvez daí a busca por "Orientação" Profissional, e quase sempre afirmam não saberem o que querem para si.

A situação tipicamente adolescente de não pertencer a uma categoria definida, muitas vezes explicitada no discurso de estar muito velho para certas coisas e muito novo para outras, fala da relação do sujeito com o tempo presente.

Analisando sua situação, o adolescente provavelmente se flagra em um momento no qual já não pode mais agir como criança, porém não se sente apto para agir como adulto.

Esta ausência de clareza em seus objetivos e planos e a certeza de não poder se manter na mesma estrutura infantil, gera no adolescente uma ansiedade típica, que se reflete no processo de escolha profissional.

Tais características encontradas nos adolescentes foram definidas por Bohoslavisky, como fase dilemática. Segundo Bohoslavisky: p.46

"Situação dilemática é aquela em que o adolescente se apercebe de que acontece alguma coisa, que existe algo importante ao seu redor, algo importante que deve fazer. Até este ponto pode ser invadido pela urgência, de tal modo que a ansiedade terá características confusas, expressas, por exemplo, no medo de que, se não escolher alguma coisa nunca deixará de ser adolescente ou nunca se separara da escola de segundo grau". 
D ao realizar a atividade da linha do tempo, na qual o adolescente é orientado a traçar uma linha com sua visão de si no passado, no presente e futuro, afirmou que o que mais lhe incomodava era a sua situação presente, pois não gostava de se sentir assim e queria mudar, queria ser mais segura.

Esta instabilidade na situação presente, típica dos momentos transitórios, pode ser atribuída à falta de imagem com a qual se identificar, ou ao contrário a existência de inúmeras imagens e assim a incerteza de qual delas adotar como sua.

È no presente que o adolescente tem que olhar para si e perceber quem é, do que gosta do que não gosta, o que sabe ou não fazer, o que dá ou não dá prazer.Mesmo sendo este um momento de muitas dúvidas, o adolescente começa a obter respostas que por vezes contradiz alguns anseios e expectativas.

Este levantamento de características subjetivas e objetivas se dará de modo mais ou menos ajustado de acordo com o grau de discernimento do adolescente. A capacidade de analisar os fatos que cercam a escolha da profissão e relacioná-los aos fatos que envolvem passado, desejo, medo, família, crença, sociedade e muitos outros aspectos que permeiam a vida do homem, passa a ser movimento natural.

O tempo futuro esta intimamente ligado ao desconhecido o que pode acarretar em medos e conseqüente estagnação frente à escolha profíssional e ao mundo adulto.

Muitos discursos trazem reflexos do medo de "quem serei eu". Escolher a profissão passa a ser uma forma de escolher quem o adolescente será.

Neste ponto da escolha muitos fatores influenciam a dinâmica interna adotada pelo adolescente. $\mathrm{O}$ ideal de ego internalizado pelo sujeito a partir de suas relações com o meio será o norteador de tal dinâmica.

Muitas vezes o adolescente que busca OP afirma que esta em busca de se conhecer para a partir de então poder escolher, outros afirmam buscar informações sobre o mercado de trabalho, cursos e profissões, ou seja, informações sobre o mundo. O movimento feito é de especulação para a partir dos dados obtidos elaborar um projeto futuro com o qual o adolescente possa se identificar e a partir de então, escolher sua profissão. que irá ser".

O movimento reflete o caminho que liga o "sujeito que é" do "sujeito

Entre o sujeito "que é" no presente e aquele "que será" no futuro existe o conceito de ideal de ego.Este embora se encontre internalizado no sujeito foi construído a partir da relação deste sujeito com o meio. Por isto é necessário falar 
de família, amigos, educação, cultura, status, pois estes fatores permearam a vida do sujeito e contribuíram para a construção do ideal de ego que ele tem hoje.

Segundo a definição de Bohoslavsky o adolescente que consegue lidar com os fatores envolvidos no processo utilizando os seus mecanismos de elaboração passa por uma fase chamada de Resolução.

Para o autor:p. 85

\begin{abstract}
"A situação de resolução esta caracterizada pela qualidade e pelo grau de ansiedades vinculadas à elaboração normal de um luto...nesta situação, o adolescente vê reativados seus antigos mecanismo postos a serviço da elaboração de situações de perda.É capaz de reconhecer seu medo e sua tristeza e, inclusive, alheações, de ambos os tipos de afeto"
\end{abstract}

A relação subjetiva que cada adolescente estabelece com o mundo e conseqüentemente com o tempo, é expressa por Lacan no conceito de tempo lógico. Para ele a relação do sujeito com o desejo, desejo este que " não faz mais do que veicular para um futuro sempre curto e limitado o que ele sustenta de uma imagem do passado", seria por definição atemporal, pois "é indestrutível e se escapa ao tempo, em que registro estaria na ordem das coisas, pois o que é uma coisa senão aquilo que dura, idêntica um certo tempo?" Sendo assim Lacan se pergunta: "Não haveria aqui lugar para se distinguir ao lado da duração, substancia das coisas em outros modos de tempo - um tempo lógico?” (p.36)

$\mathrm{O}$ inconsciente para Freud é descrito como atemporal, não existe passado e futuro mas apenas o aqui e agora. A realização de um desejo não pode ser postergada. Se o tempo externo, não vigora em termos inconscientes e como já foi dito a leitura que cada um tem do mundo perpassa o conceito de tempo, como entender a relação do inconsciente com a realidade.A definição de tempo lógico, elaborada por Lacan veio de encontro a esta questão, pois indica que para cada sujeito existe um momento de ver as coisas, de compreendê-las e de elaborá-las. Cada um tem o seu próprio tempo, e este não se enquadra à mensuração convencionada.

Se o tempo é peculiar ao sujeito, a relação que ele mantém com o tempo fala de sua estrutura.

Cada um entende o tempo de acordo com o seu tempo lógico, e, portanto existem milhões de possibilidades.A prática em orientação profissional traz alguns exemplos.

O que muitos adolescentes trazem, logo no primeiro encontro é a necessidade de uma escolha perfeita, pois esta escolha definira quem o sujeito será, definirá se será ou não feliz na vida adulta. 
Frases como não posso escolher errado, pois não tenho tempo a perder, freqüentemente aparecem nos grupos de OP.

A impossibilidade de resgatar o tempo passado acaba por gerar uma ansiedade em relação à escolha profissional, no sentido de que uma vez feita a escolha errada na adolescência, jamais se terá a adolescência de novo para escolher novamente outro caminho.

A analogia de que se caminha para frente em uma estrada que as vezes se divide e uma vez escolhido um caminho os outros serão deixados para trás fala desta relação com o tempo que caminha para um lugar do qual não se pode voltar.O desejo de voltar no tempo e no passado e poder alterar o futuro é uma fantasia que pertence, não apenas aos adolescentes, mas também à vida adulta.Muitos são os filmes e livros que realizam tais fantasias.

Outra forma de lidar com o tempo percebe-se na conduta de muitos adolescentes que se angustiam, pois não conseguem imaginar que em relação ao seu eu presente e o seu profissional idealizado existe uma lacuna temporal que será preenchida com um dia de cada vez. Não ter esta noção faz com que eles se julguem inaptos para exercer a profissão escolhida, pois não tem as habilidades requeridas pela profissão que escolheram.

Quando o adolescente se sente inapto para ser um adulto ou um profissional aparece no discurso o conceito de vocação. Este discurso, de habilidades inatas, sustentado pela humanidade ao longo de décadas, e respaldado pela própria psicologia em algumas de suas vertentes, passa a ser utilizado pelo adolescente que não vê no tempo a possibilidade de um vir a ser. A profissão passa a ser algo, não construído ao longo de tempo e estudos, mas sim algo que se deva encontrar em "escavações genéticas"e testes de personalidade.

Sofrer por achar que não dará conta do futuro escolhido, fala não apenas de ideal de eu, mas também da forma como o sujeito encara e administra o conceito de tempo.

Alguns adolescentes trazem a sensação de que o dia não tem tempo suficiente para se realizar todos os afazeres. Não é possível estudar para o vestibular e viver ao mesmo tempo.Independente da escolha feita o adolescente a culpa por não ter feito tudo sempre aparece.

Ter tempo para trabalhar e fazer o que gosta, também aparece muito no discurso.Muitos adolescentes acabam por fazer disto um parâmetro para a escolha profissional. Escolhem profissões envolvidas com as atividades que consideram prazerosas pois assim poderão trabalhar enquanto se divertem ou vice versa.Administrar o tempo, e conseqüentemente a vida é tema cuja importância se reflete no ditado "existe tempo para plantar e tempo para colher... agora é tempo para plantar"A noção expressa por esta fase de que as coisas podem ser feitas a 
seu momento e que existe para isto a necessidade de paciência e temperança é algo que para os adolescentes é dom somente para os sábio idosos.

$\mathrm{O}$ adolescente por sua vez se percebe no tempo de escolher, sabe também de certa forma que isto vai passar. Quando busca Orientação Profissional, busca um apoio para passar por este momento da vida, caso contrario buscaria terapia, e ao trabalhar em grupo percebe que este momento é e pode ser compartilhado com outros.

Os mecanismos de identificação descritos pelos estudiosos de grupos vigoram também, obviamente, no que cerne o conceito de tempo e o modo de lidar com ele.

O grupo ao contar uma história é capaz de fazer com que os personagens morram e reencarnem, morram e tenha filhos que continuem a história. Este exemplo reflete que o grupo em si também tem uma relação com o tempo e é capaz de expressá-la ao longo das atividades.

O Orientador Profissional, ao longo do seu trabalho também ira lidar com a questão do tempo. A seqüência das atividades e temas selecionados para o processo de orientação profissional, de certo modo fala das expectativas do orientador em relação ao ritmo adotado pelo grupo.

O tempo lógico do adolescente vai ditar o ritmo do processo e não, ao contrário do que se pensa, o tempo real ou o tempo lógico do orientador.

No decorrer do trabalho grupal, o orientador deve perceber a relação do sujeito com o tempo e principalmente o que isto interfere na escolha profissional.

Para Bohoslavisky a crise na adolescência tem a ver com a desestruturação e reestruturação da personalidade e afirma que o tempo é a primeira fase na qual a personalidade vai se estruturar, pois o sujeito se identifica com projetos futuros que reconhece como se fossem seus. Saber de si e saber de suas possibilidades permite ao sujeito desejar e se reconhecer neste desejo.

O que curiosamente Bohoslavsky chamou de "escolha madura" já na terminologia adotada remete a uma alteração gradativa, uma evolução ao longo do tempo, um maturar rumo a uma outra fase, sendo assim não há como ignorar o tempo.

\section{Referência Bibliográfica:}

BOHOSLASKY; Rodolfo Orientação Profissional: a estratégia clínica Martins Fontes São Paulo -1998.

FREUD. S. Obras Completas de S.Freud. Ed Standard. Recordar repetir e elaborar, 1917. São Paulo, Imago, 1995.

MICHAELIS: dicionário on-line 
LACAN; Jean J. Seminário 11 -edição on line

LAPLANCHE E PONTALIS : Vocabulário de psicanálise- São Paulo- Martins Fontes 1998

LASSANCE, M. C. et al.Técnicas para o trabalho de orientação profissional. Porto Alegre: Ed. UFRGS, 1999.

UFPR :Normas de Apresentação de Trabalho, v.4., $2^{\circ}$ ed., Editora UFPR, Curiitiba, 